\title{
STUDI EFISIENSI PEMBERIAN AIR IRIGASI SALURAN SEKUNDER SIDOKERTO KECAMATAN BUMI RATU NUBAN KABUPATEN LAMPUNG TENGAH, PROVINSI LAMPUNG
}

\author{
NOVA LITA PURNAMASARI ${ }^{1}$, Dr. Any Nurhasanah, ST., MT. ${ }^{2}$ \\ Program Studi Teknik Sipil, Fakultas Teknik, Universitas Bandar Lampung, \\ J1. Zainal Abidin Pagar Alam No. 26 Labuhan Ratu Bandar Lampung, 0721-701979 \\ E-mail:novalita@studentubl.ac.id: \\ any_nurhasanah@ubl.ac.id
}

\begin{abstract}
ABSTRAK
Saluran sekunder merupakan salah satu struktur irigasi yang penting dalam pemberian air hingga sampai kepetak-petak pertanian. Pemberian air irigasi dianggap efektif jika petak-petak pertanian menerima air secara adil dan merata tanpa terjadi kekurangan ataupun kelebihan air.

Pemberian air irigasi secara efisien bukanlah pekerjaan yang mudah dan sederhana karena banyak faktor yang dapat mempengaruhi dalam penyediaan dan pemberian air irigasi. Dampak pemberian air irigasi yang kurang efisian dapat mengurangi produktifitas pertanian yang mengakibatkan penurunan ketahanan pangan dan kesejahteraan masyarakat, petani khususnya.

Desain penelitian menggunakan pendekatan kuantitatif bersifat deskriptif yaitu menjelaskan kondisi efisiensi pemberian air irigasi di Saluran Sekunder Sidokerto, Kecamatan Bumi Ratu Nuban, Kabupaten Lampung Tengah, Provinsi Lampung. Data yang digunakan dalam studi ini adalah luas penampang saluran (A), kecepatan rata-rata aliran air (VAv), debit air di saluran (Q), kebutuhan air irigasi untuk lahan pertanian dan tanaman, dan efisiensi pemberian air irigasi pada setiap saluran (E). Berdasarkan hasil penelitian ini, saluran irigasi Sekunder Sidokerto BSk.1 memiliki panjang saluran sekunder 444 m', luas area irigasi 62 Ha dengan debit aktual 74,235 liter/detik dan nilai efisiensi air 98\%. BSk.2 memiliki panjang saluran sekunder 664 m', luas area irigasi

189 Ha dengan debit aktual 86,940 liter/detik, dan nilai efisien air 100\%. BSk.3 memiliki panjang saluran sekunder $866 \mathrm{~m}$ ', luas area irigasi $131 \mathrm{Ha}$ memiliki debit aktual 63,504 liter/detik dan nilai efisien air 100\%, maka sudah efisien dalam mencukupi kebutuhan air bahkan berlebih sesuai standar. Sedangkan pada Saluran Sekunder BSk.4 memiliki panjang saluran sekunder 333 m', luas area irigasi $85 \mathrm{Ha}$, dengan debit aktual 91,080 liter/detik, dan nilai efisien air 87\%, dinyatakan belum terlalu efektif dalam pemenuhan kebutuhan air irigasi karena dibawah standar.
\end{abstract}

Kata kunci : Saluran Sekunder, Debit Air, Kinerja Saluran, Efisiensi Air Irigasi. 


\section{PENDAHULUAN}

Saluran sekunder Sidokerto yang merupakan bagian jaringan Daerah Irigasi Bekri yang berada di bawah naungan Balai Besar Wilayah Sungai Mesuji Sekampung (BBWS-MS) Provinsi Lampung telah di bangun lebih dari 11 tahun yang lalu yang jumlah total areal pertanian baku seluas 251 Ha yang berada di Kampung Sidokerto, Kecamatan Bumi Ratu Nuban, Kabupaten Lampung Tengah. Pada saat ini kondisi jaringan irigasi tersebut kurang berfungsi secara optimal. Hal ini di karenakan faktor umur bangunan serta kurangnya kesadaran para petani untuk membantu merawat dan menjaga bangunan tersebut, sehingga banyak fasilitas dan bangunan jaringan irigasi yang rusak. Akibat kerusakan tersebut mengakibatkan permasalahan kehilangan air disepanjang jaringan irigasi sekunder Sidokerto tersebut. Untuk membantu kemudahan dalam menangani masalah ini, penulis melakukan pengamatan langsung untuk membantu menginformasikan masalah yang ada di lapanngan. Pengurangan jumlah debit ini tampak dari tidak terpenuhinya kebutuhan air irigasi sesuai dengan perencanaan awal. Saat ini debit yang masuk kesaluran sekunder tersebut mengalami penurunan drastis dari awal perencanaan yang direncanakan. Untuk memenuhi kembali kebutuhan air irigasi tersebut, tentunya perlu mengembalikan fungsi jaringan irigasi yang telah ada dan penyesuaian antara luas areal pertanian dengan besarnya debit yang ada pada jaringan irigasi. Upaya yang dapat di lakukan adalah dengan mengadakan perbaikan/rehabilitasi pada pola pelayanan irigasi sedemikian rupa sehingga debit yang di rencanakan bisa memenuhi kebutuhan air untuk irigasi yang nyata sesuai dengan kondisi di lapangan.

\section{METODE PENELITIAN}

\section{Peralatan yang Digunakan}

Beberapa alat dan bahan untuk menunjang pelaksanaan penelitian di lapangan adalah Stop Watch yang digunakan untuk mengetahui awal dan akhir waktu pengamatan, Alat tulis, Alat pengukur (meteran).

\section{Penentuan Waktu Penelitian}

Pencatatan dimensi saluran dan kecepatan air dilakukan pada saat musim tanam II dan usia tanaman berumur 1 (satu) bulan. Data yang diperoleh dari survey lapangan dipakai untuk perhitungan luas penampang (A), kecepatan rata-rata (Vav), Debit air (Q), Kebutuhan Air Tiap Petak Sawah, Efisiensi Air Irigasi (E). Waktu penelitian dilakukan mulai dari Pukul 08.00-16.00 selama 3 hari.

\section{Metode Pengumpulan Data}

Data Primer yaitu data yang diperoleh secara langsung dari sumbernya atau survey langsung kelapangan dengan menggunakan alat ukur untuk mengukur, alat tulis untuk mencatat, kamera sebagai alat dokumentasi di musim tanam II. Pengumpulan data primer dilakukan dengan cara survei, seperti Data dimensi saluran, tinggi muka air, dan kecepatan air.

Data Sekunder yaitu data pendukung yang diperoleh dari dinas terkait dan sumber lainnya, seperti skema jaringan saluran sekunder sidokerto (BSk) dan peta rupa bumi daerah sidokerto.

\section{Langkah-Langkah Pengukuran}

Pengukuran dimensi saluran dan tingi muka air yaitu mengukur lebar atas saluran (ba), lebar bawah saluran (bb), 
mengukur tinggi saluran saluran (hs), tinggi muka air (hp), menentukan titik awal pengukuran kecepatan aliran, menyiapkan alat pelampung sebagai parameter dan dihanyutkan sesuai titik pengukuran.

\section{HASIL DAN PEMBAHASAN}

\section{Data Saluran sekunder Sidokerto (BSk)}

BSk.1 panjang saluran sekunder 444 meter dan luas area irigasi 62 Ha. BSk.2 dengan panjang saluran sekunder 664 meter dan luas area irigasi 189 Ha. BSk.3 dengan panjang saluran sekunder 866 meter dan luas area irigasi $131 \mathrm{Ha}$. BSk.4 dengan panjang saluran sekunder 333 meter dan luas area irigasi $85 \mathrm{Ha}$.

Tabel 4.1. Luas Penampang Saluran (A)

\begin{tabular}{|c|c|c|c|c|c|c|}
\hline $\mathbf{N o}$ & $\mathbf{K o d e}$ & $\mathbf{b a}$ & $\mathbf{b b}$ & $\mathbf{h s}$ & $\mathbf{h p}$ & Luas Penampang (A) \\
& Saluran & $\left(\mathbf{m}^{\prime}\right)$ & $\mathbf{( \mathbf { m } ^ { \prime } )}$ & $\mathbf{( \mathbf { m } ^ { \prime } )}$ & $\mathbf{( \mathbf { m } ^ { \prime } )}$ & $\mathbf{( \mathbf { m } ^ { 2 } )}$ \\
\hline a & b & c & d & e & f & $\mathrm{g}=(\mathbf{c}+\mathrm{d}) / 2 * \mathrm{f}$ \\
\hline 1 & BSk.1 & 2,200 & 0,600 & 0,800 & 0,250 & 0,350 \\
\hline 2 & BSk.2 & 2,200 & 0,600 & 0,800 & 0,250 & 0,350 \\
\hline 3 & BSk.3 & 1,900 & 0,500 & 0,700 & 0,200 & 0,240 \\
\hline 4 & BSk.4 & 1,750 & 0,450 & 0,600 & 0,200 & 0,220 \\
\hline & & & & & & \\
\hline
\end{tabular}

Tabel 4.2. Kecepatan Aliran Setiap Saluran

\begin{tabular}{|c|c|c|c|c|c|}
\hline No & Kode & $\mathbf{V}$ (titik 1) & $\mathbf{V}$ (titik 2) & $\mathbf{V}$ (titik 3) & $\mathbf{V}$ \\
& Saluran & $(\mathbf{m} / \mathbf{s})$ & $(\mathbf{m} / \mathbf{s})$ & $(\mathbf{m} / \mathbf{s})$ & $(\mathbf{m} / \mathbf{s})$ \\
\hline a & b & $\mathrm{c}$ & $\mathrm{d}$ & $\mathrm{e}$ & $\mathrm{f}=(\mathrm{c}+\mathrm{d}+\mathrm{e}) / 3$ \\
\hline 1 & BSk.1 & 0,236 & 0,235 & 0,236 & 0,236 \\
\hline 2 & BSk.2 & 0,277 & 0,275 & 0,276 & 0,276 \\
\hline 3 & BSk.3 & 0,295 & 0,293 & 0,294 & 0,294 \\
\hline 4 & BSk.4 & 0,470 & 0,450 & 0,460 & 0,460 \\
\hline & & & & & \\
\hline
\end{tabular}

Tabel 4.3. Kecepata Rata-Rata (Vav)

\begin{tabular}{|c|c|c|c|c|}
\hline \multirow{2}{*}{ No } & Kode & Kecepatan aliran air (V) & Koefisien & Kecepatan rata-rata (Vav) \\
\cline { 2 - 5 } & Saluran & $(\mathbf{c m} / \mathbf{s})$ & $\mathbf{k}$ & $\mathbf{( c m / s )}$ \\
\hline a & b & c & d & $\mathrm{e}=\left(\mathrm{c}^{*} \mathrm{~d}\right)$ \\
\hline 1 & BSk.1 & 23,567 & 0,900 & 21,210 \\
\hline 2 & BSk.2 & 27,600 & 0,900 & 24,840 \\
\hline 3 & BSk.3 & 29,400 & 0,900 & 26,460 \\
\hline 4 & BSk.4 & 46,000 & 0,900 & 41,400 \\
\hline & & & & \\
\hline
\end{tabular}

Tabel 4.4. Debit Aktual Saluran (Debit Hasil Pengukuran)

\begin{tabular}{|c|c|c|c|c|c|}
\hline \multirow{2}{*}{ No } & \multirow{2}{*}{$\begin{array}{l}\text { Kode } \\
\text { Saluran }\end{array}$} & \multirow{2}{*}{$\begin{array}{c}\text { Luas Penampang (A) } \\
(\mathrm{m} 2)\end{array}$} & \multirow{2}{*}{$\begin{array}{c}\text { Kecepatan rata-rata } \\
\text { (Vav) } \\
(\mathrm{m} / \mathrm{s})\end{array}$} & \multicolumn{2}{|c|}{$\mathbf{Q}_{\text {aktual }}$} \\
\hline & & & & $\left(\mathrm{m}^{3} / \mathrm{s}\right)$ & $(\mathrm{ltr} / \mathrm{s})$ \\
\hline $\mathrm{a}$ & b & $\mathrm{c}$ & d & $\mathrm{e}=\mathrm{c}^{*} \mathrm{~d}$ & $f=e / 1000$ \\
\hline 1 & BSk.1 & 0,350 & 0,212 & 0,074 & 74,235 \\
\hline 2 & BSk.2 & 0,350 & 0,248 & 0,087 & 86,940 \\
\hline 3 & BSk. 3 & 0,240 & 0,265 & 0,064 & 63,504 \\
\hline 4 & BSk.4 & 0,220 & 0,414 & 0,091 & 91,080 \\
\hline & & & & & \\
\hline
\end{tabular}

Tabel 4.5. Kebutuhan Air Tiap Petak Sawah Umur Padi 0,5 Bulan

\begin{tabular}{|c|c|c|c|c|r|}
\hline \multirow{2}{*}{ No } & Kode & $\begin{array}{c}\text { Kebutuhan Air Saat } \\
\text { Umur 0,5 Bulan }\end{array}$ & Luas Pe tak & \multicolumn{2}{|c|}{$\begin{array}{c}\text { Kebutuhan Air Tiap } \\
\text { Pe tak }\end{array}$} \\
\cline { 5 - 6 } & Saluran & (ltr/s/ha) & (ha) & (ltr/s) & \multicolumn{1}{|c|}{$\left(\mathbf{m}^{3} / \mathbf{s}\right)$} \\
\hline a & $\mathrm{b}$ & $\mathrm{c}$ & $\mathrm{d}$ & $\mathrm{e}=\mathrm{c}^{*} \mathrm{~d}$ & $\mathrm{f}=\mathrm{e} / 1000$ \\
\hline 1 & BSk.1 & 1,200 & 62,000 & 74,400 & 0,074 \\
\hline 2 & BSk.2 & 1,200 & 58,000 & 69,600 & 0,070 \\
\hline 3 & BSk.3 & 1,200 & 46,000 & 55,200 & 0,055 \\
\hline 4 & BSk.4 & 1,200 & 85,000 & 102,000 & 0,102 \\
\hline & & & & & \\
\hline
\end{tabular}

Tabel 4.6. Kebutuhan Air Tiap Petak Sawah Umur Padi 1 Bulan

\begin{tabular}{|c|c|c|c|c|r|}
\hline \multirow{2}{*}{ No } & \multirow{2}{*}{ Kode } & $\begin{array}{r}\text { Kebutuhan Air Saat } \\
\text { Umur 1,0 Bulan }\end{array}$ & \multirow{2}{*}{ Luas Petak } & \multicolumn{2}{|c|}{$\begin{array}{r}\text { Kebutuhan Air Tiap } \\
\text { Petak }\end{array}$} \\
\cline { 6 - 7 } & Saluran & (Itr/s/ha) & (ha) & (ltr/s) & $\left(\mathbf{m}^{3} / \mathbf{s}\right)$ \\
\hline a & b & c & $\mathrm{d}$ & $\mathrm{e}=\mathrm{c}^{*} \mathrm{~d}$ & $\mathrm{f}=\mathrm{e} / 1000$ \\
\hline 1 & BSk.1 & 1,200 & 62,000 & 74,400 & 0,074 \\
\hline 2 & BSk.2 & 1,200 & 58,000 & 69,600 & 0,070 \\
\hline 3 & BSk.3 & 1,200 & 46,000 & 55,200 & 0,055 \\
\hline 4 & BSk.4 & 1,200 & 85,000 & 102,000 & 0,102 \\
\hline & & & & & \\
\hline
\end{tabular}

Tabel 4.7. Kebutuhan Air Tiap Petak Sawah Umur Padi 1,5 Bulan

\begin{tabular}{|c|c|c|c|c|r|}
\hline \multirow{2}{*}{ No } & \multirow{2}{*}{ Kode } & $\begin{array}{c}\text { Kebutuhan Air Saat } \\
\text { Umur 1,5 Bulan }\end{array}$ & \multirow{2}{*}{ Luas Pe tak } & \multicolumn{2}{|c|}{$\begin{array}{c}\text { Kebutuhan Air Tiap } \\
\text { Pe tak }\end{array}$} \\
\cline { 5 - 6 } & Saluran & (Itr/s/ha) & (ha) & (ltr/s) & \multicolumn{1}{|c|}{$\left(\mathbf{m}^{3} / \mathbf{s}\right)$} \\
\hline a & b & $\mathrm{c}$ & $\mathrm{d}$ & $\mathrm{e}=\mathrm{c}^{*} \mathrm{~d}$ & $\mathrm{f}=\mathrm{e} / 1000$ \\
\hline 1 & BSk.1 & 1,320 & 62,000 & 81,840 & 0,082 \\
\hline 2 & BSk.2 & 1,320 & 58,000 & 76,560 & 0,077 \\
\hline 3 & BSk.3 & 1,320 & 46,000 & 60,720 & 0,061 \\
\hline 4 & BSk.4 & 1,320 & 85,000 & 112,200 & 0,112 \\
\hline & & & & & \\
\hline
\end{tabular}

Tabel 4.8. Kebutuhan Air Tiap Petak Sawah Umur Padi 2 Bulan

\begin{tabular}{|c|c|c|c|c|r|}
\hline \multirow{2}{*}{ No } & Kode & $\begin{array}{c}\text { Kebutuhan Air Saat } \\
\text { Umur 2,0 Bulan }\end{array}$ & \multirow{2}{*}{ Luas Petak } & \multicolumn{2}{|c|}{$\begin{array}{c}\text { Kebutuhan Air Tiap } \\
\text { Petak }\end{array}$} \\
\cline { 5 - 7 } & Saluran & (Itr/s/ha) & (ha) & (Itrr/s) & \multicolumn{1}{c|}{$\left(\mathbf{m}^{3} / \mathbf{s}\right)$} \\
\hline a & b & $\mathrm{c}$ & $\mathrm{d}$ & $\mathrm{e}=\mathrm{c}^{*} \mathrm{~d}$ & $\mathrm{f}=\mathrm{e} / 1000$ \\
\hline 1 & BSk.1 & 1,400 & 62,000 & 86,800 & 0,0868 \\
\hline 2 & BSk.2 & 1,400 & 58,000 & 81,200 & 0,0812 \\
\hline 3 & BSk.3 & 1,400 & 46,000 & 64,400 & 0,0644 \\
\hline 4 & BSk.4 & 1,400 & 85,000 & 119,000 & 0,1190 \\
\hline & & & & & \\
\hline
\end{tabular}


Tabel 4.9. Kebutuhan Air Tiap Petak Sawah Umur Padi 2,5 Bulan

\begin{tabular}{|c|c|c|c|c|r|}
\hline \multirow{2}{*}{ No } & \multirow{2}{*}{ Kode } & $\begin{array}{c}\text { Kebutuhan Air Saat } \\
\text { Umur 2,5 Bulan }\end{array}$ & Luas Petak & \multicolumn{2}{|c|}{$\begin{array}{c}\text { Kebutuhan Air Tiap } \\
\text { Petak }\end{array}$} \\
\cline { 5 - 6 } & Saluran & (Itr/s/ha) & (ha) & (Itr/s) & \multicolumn{1}{c|}{$\left(\mathbf{m}^{\mathbf{3}} / \mathbf{s}\right)$} \\
\hline a & $\mathrm{b}$ & $\mathrm{c}$ & $\mathrm{d}$ & $\mathrm{e}=\mathrm{c}^{*} \mathrm{~d}$ & $\mathrm{f}=\mathrm{e} / 1000$ \\
\hline 1 & BSk.1 & 1,350 & 62,000 & 83,700 & 0,084 \\
\hline 2 & BSk.2 & 1,350 & 58,000 & 78,300 & 0,078 \\
\hline 3 & BSk.3 & 1,350 & 46,000 & 62,100 & 0,062 \\
\hline 4 & BSk.4 & 1,350 & 85,000 & 114,750 & 0,115 \\
\hline & & & & & \\
\hline
\end{tabular}

Tabel 4.10 Kebutuhan Air Tiap Petak Sawah Umur Padi 3 Bulan

\begin{tabular}{|c|c|c|c|c|r|}
\hline \multirow{2}{*}{ No } & Kode & $\begin{array}{c}\text { Kebutuhan Air Saat } \\
\text { Umur 3,0 Bulan }\end{array}$ & Luas Petak & \multicolumn{2}{|c|}{$\begin{array}{c}\text { Kebutuhan Air Tiap } \\
\text { Petak }\end{array}$} \\
\cline { 5 - 6 } & Saluran & (Itr/s/ha) & (ha) & (Itr/s) & \multicolumn{1}{c|}{$\left(\mathbf{m}^{\mathbf{3}} / \mathbf{s}\right)$} \\
\hline a & $\mathrm{b}$ & $\mathrm{c}$ & $\mathrm{d}$ & $\mathrm{e}=\mathrm{c}^{*} \mathrm{~d}$ & $\mathrm{f}=\mathrm{e} / 1000$ \\
\hline 1 & BSk.1 & 1,250 & 62,000 & 77,500 & 0,078 \\
\hline 2 & BSk.2 & 1,250 & 58,000 & 72,500 & 0,073 \\
\hline 3 & BSk.3 & 1,250 & 46,000 & 57,500 & 0,058 \\
\hline 4 & BSk.4 & 1,250 & 85,000 & 106,250 & 0,106 \\
\hline & & & & & \\
\hline
\end{tabular}

Tabel 4.11 Kebutuhan Air Tiap Petak Sawah Umur Padi 3,5 Bulan

\begin{tabular}{|c|c|c|c|c|r|}
\hline \multirow{2}{*}{ No } & \multirow{2}{*}{ Kode } & $\begin{array}{c}\text { Kebutuhan Air Saat } \\
\text { Umur 3,5 Bulan }\end{array}$ & Luas Pe tak & \multicolumn{2}{|c|}{$\begin{array}{c}\text { Kebutuhan Air Tiap } \\
\text { Pe tak }\end{array}$} \\
\cline { 2 - 6 } & Saluran & (Itr/s/ha) & (ha) & (ltr/s) & ( $\left.^{\mathbf{3}} / \mathbf{s}\right)$ \\
\hline a & b & c & d & $\mathrm{e}=\mathrm{c}^{*} \mathrm{~d}$ & $\mathrm{f}=\mathrm{e} / 1000$ \\
\hline 1 & BSk.1 & 1,120 & 62,000 & 69,440 & 0,069 \\
\hline 2 & BSk.2 & 1,120 & 58,000 & 64,960 & 0,065 \\
\hline 3 & BSk.3 & 1,120 & 46,000 & 51,520 & 0,052 \\
\hline 4 & BSk.4 & 1,120 & 85,000 & 95,200 & 0,095 \\
\hline & & & & & \\
\hline
\end{tabular}

Tabel 4.12 Kebutuhan Air Tiap Petak Sawah Umur Padi 4 Bulan

\begin{tabular}{|c|c|c|c|c|c|}
\hline \multirow{2}{*}{ No } & \multirow{2}{*}{ Kode } & $\begin{array}{c}\text { Kebutuhan Air Saat } \\
\text { Umur 4,0 Bulan }\end{array}$ & \multirow{2}{*}{$\begin{array}{c}\text { Luas Petak } \\
\text { (ha) }\end{array}$} & \multicolumn{2}{|c|}{$\begin{array}{c}\text { Kebutuhan Air Tiap } \\
\text { Petak }\end{array}$} \\
\cline { 5 - 6 } & Saluran & (Itrr/s) & $\left(\mathbf{m}^{\mathbf{3}} \mathbf{s} \mathbf{s}\right)$ \\
\hline $\mathrm{a}$ & $\mathrm{b}$ & $\mathrm{c}$ & $\mathrm{d}$ & $\mathrm{e}=\mathrm{c}^{*} \mathrm{~d}$ & $\mathrm{f}=\mathrm{e} / 1000$ \\
\hline 1 & BSk.1 & 0,000 & 62,000 & 0,000 & \\
\hline 2 & BSk.2 & 0,000 & 58,000 & 0,000 & \\
\hline 3 & BSk.3 & 0,000 & 46,000 & 0,000 & \\
\hline 4 & BSk.4 & 0,000 & 85,000 & 0,000 & \\
\hline & & & & & \\
\hline
\end{tabular}

Tabel 4.13. Kebutuhan Air di Saluran dan Petak Sawah

\begin{tabular}{|c|c|c|c|c|c|}
\hline \multirow[t]{2}{*}{ No } & Nama & Luas Petak & $\begin{array}{c}\text { Kebutuhan } \\
\text { Debit Air Tiap } \\
\text { Petak }\end{array}$ & $\begin{array}{c}\text { Kode } \\
\text { Saluran }\end{array}$ & $\begin{array}{c}\text { Debit Air } \\
\text { Aktual }\end{array}$ \\
\hline & Petak & (ha) & (ltr/dtk) & & (Itr/dtk) \\
\hline $\mathrm{a}$ & $\mathrm{b}$ & $\mathrm{c}$ & $\mathrm{d}$ & $\mathrm{e}=\mathrm{c} * \mathrm{~d}$ & $f=e / 1000$ \\
\hline 1 & \begin{tabular}{|l|} 
Petak.1 \\
\end{tabular} & 62,000 & 74,400 & \begin{tabular}{ll|} 
BSk.1 \\
\end{tabular} & 74,235 \\
\hline 2 & \begin{tabular}{|l|} 
Petak.2 \\
\end{tabular} & 58,000 & 69,600 & BSk.2 & 86,940 \\
\hline 3 & \begin{tabular}{|l|} 
Petak.3 \\
\end{tabular} & 46,000 & 55,200 & $\begin{array}{ll}\text { BSk.33 } \\
\end{array}$ & 63,504 \\
\hline 4 & \begin{tabular}{|l|} 
Petak.4 \\
\end{tabular} & 85,000 & 102,000 & BSk.4 & 91,080 \\
\hline & Jumlah & 251,000 & 301,200 & & 315,759 \\
\hline
\end{tabular}

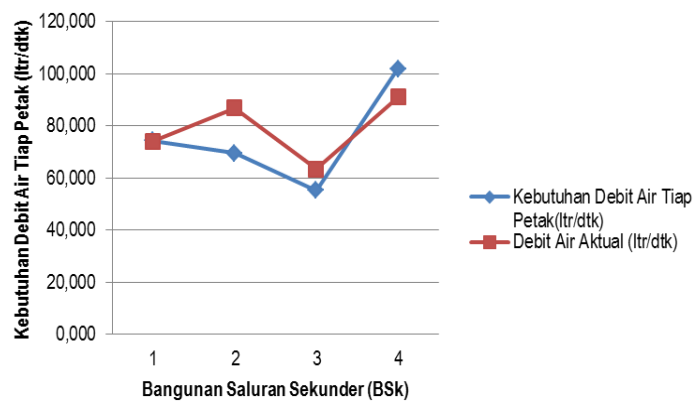

Gambar 4.2. Diagram Kebutuhan Air di Saluran dan Petak Sawah

Tabel 4.14. Persentase Efisiensi Irigasi

\begin{tabular}{|c|c|c|c|c|}
\hline \multirow{2}{*}{ No } & Kode & Adb & Asa & Efisiensi Pengairan \\
& Saluran & (ltr/dtk) & (ltr/dtk) & (\%) \\
\hline a & b & c & d & e = (d/c)*100 \\
\hline 1 & BSk.1 & 75,144 & 73,493 & 98 \\
\hline 2 & BSk.2 & 70,644 & 70,334 & 100 \\
\hline 3 & BSk.3 & 56,028 & 55,884 & 100 \\
\hline 4 & BSk.4 & 103,122 & 90,078 & 87 \\
\hline & & & & \\
\hline
\end{tabular}

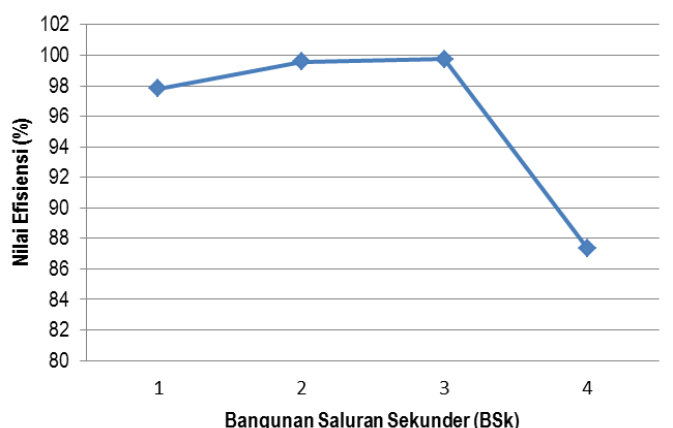
$\begin{array}{ccc}\text { Gambar } & 4.3 . \quad \text { Diagram } & \text { Persentase } \\ & \text { Efisiensi Saluran } & \text { Sekunder } \\ \text { (BSk) } & & \end{array}$

Berdasarkan tabel dan diagaram di atas saluran BSk.1 dengan nilai efisiensi $98 \%$, BSk.2 dengan nilai efisiensi $100 \%$, BSk.3 dengan nilai efisiensi dengan nilai efisiensi $100 \%$ sudah memenuhi standart (saluran sekunder 90\%) menurut standarisasi Direktorat Jendral Pengairan. Saluran BSk.4 dengan nilai efisiensi $87 \%$ belum memenuhi standart efisiensi pengaliran air irigasi. 


\section{PENUTUP}

\section{Kesimpulan}

Berdasarkan hasil penelitian ini, saluran irigasi Sekunder Sidokerto BSk.1 memiliki panjang saluran sekunder 444 m', luas area irigasi $62 \mathrm{Ha}$ dengan debit aktual 74,235 liter/detik dan nilai efisiensi air 98\%. BSk.2 memiliki panjang saluran sekunder $664 \mathrm{~m}$ ', luas area irigasi $189 \mathrm{Ha}$ dengan debit aktual 86,940 liter/detik, dan nilai efisien air $100 \%$. BSk.3 memiliki panjang saluran sekunder 866 m', luas area irigasi 131 Ha memiliki debit aktual 63,504 liter/detik dan nilai efisien air 100\%, maka sudah efisien dalam mencukupi kebutuhan air bahkan berlebih sesuai standar. Sedangkan pada Saluran Sekunder BSk.4 memiliki panjang saluran sekunder $333 \mathrm{~m}$, luas area irigasi $85 \mathrm{Ha}$, dengan debit aktual 91,080 liter/detik, dan nilai efisien air 87\%, dinyatakan belum terlalu efektif dalam pemenuhan kebutuhan air irigasi karena dibawah standar.

\section{Saran}

1. Sebaiknya untuk Dinas Pertanian, Dinas Pengairan maupun Balai Besar Wilayah Mesuji Sekampung melakukan peninjauan lokasi agar dapat menindak lanjuti permasalahan kerusakan struktur yang terjadi pada saluran sekunder tersebut.

2. Perlunya sosialisasi secara berkelanjutan kepada petani agar mematuhi managemen pendistribusian dan kedisiplinan dalam penggunaan air irigasi serta kesadaran akan pentingnya perawatan saluran tersebut secara rutin dan berkala.

3. Evaluasi penetapan pola tanam dengan tepat sehingga memudahkan petani dalam mengoptimalkan lahan pertanian yang ada.

\section{DAFTAR PUSTAKA}

Mawardi, Erman. 2007. Desain Hidrolik Bangunan Irigasi. Jakarta: Alfabeta Peraturan Pemerintah No. 25, 2001. Pengelolaan Kualitas Air

Rangga A.P. Mochamad. 2012. Studi Efisiensi Pemberian Air Irigasi Desa Kutoharjo, Kecamatan Pati, Kabupaten Pati, Jawa Tengah. Skripsi. Semarang: Fakultas Teknik Universitas Negeri Semarang.

Sarono, dkk., 2007. Fungsi dan Manfaat Bendungan. Semarang: Universitas Diponegoro.

Soemarto, CD. 1986. Hidrologi Teknik. Surabaya : Usaha Nasional.

Triatmojo, B. 1996. Hidraulika I, Fakultas Teknik Universitas Gajahmada. Yogyakarta.

Sosrodarsono, S. 2003. Hidrologi untuk Pertanian. Jakarta: Pradya Paramita.

Sudjarwadi. 1987. Dasar-Dasar Teknik Irigasi. Fakultas Teknik Universitas Gajahmada.

Yogyakarta.

Tancung, Andi Baso dan Kurdi, M. Gufron. 2005. Pengelolaan Kualitas Air dalam Budi Daya Perairan. Makasar: Rineka Cipta.

Undang-Undang No. 07, 2004. Sumber Daya Air. 